$\mathrm{N}^{\mathrm{G}}$-NITRO-L-ARGININE methyl ester (L-NAME) has been used extensively as a paradigmatic inhibitor of NO synthase and has been shown to cause antinociception in several experimental models. We describe here how L-NAME produced a dose-dependent antinociceptive effect when injected intraperitoneally in the mouse after acetic acid induced writhings, or intraplantarly in the rat paw pressure hyperalgesia induced by carrageenin or prostaglandin E2. In contrast another NO synthase inhibitor, $\mathrm{N}^{\mathrm{G}}$-monomethyl-L-arginine (L-NMMA), had no sign ificant effect per se but inhibited L-NAME systemic induced antinociception in mice and local induced antinociception in the rat paw hyperalgesia test. D-NAME had no antinociceptive effect upon carrageenin-induced hyperalgesia. Pretreatment of the paws with two in hibitors of guanylate cyclase, methylene blue (MB) and $1 \mathrm{H}-:[1,2,4]-$ oxadiazolo-: $[4,3-\mathrm{a}]$ quinoxalin-1-one (ODQ) abolished the antinociceptive effect of L-NAME. L-Argin in e and the cGMP phosphodiesterase in hibitor, MY 5445 significantly en an ced the L-NAME antinociceptive effect. The central antinociceptive effect of L-NAME was blocked by co-adm in is tration of L-NMMA, ODQ and MB. The present series of experiments shows that L-NAME, but not L-NMMA, has an antinociceptive effect. It can be suggested that L-NAME causes the antinociceptive effect by stimulation of the arginine/ NO/ cGMP pathway, since the an tinociceptive effect of L-NAME can be antagonized by L-NMMA and abolished by the guanylate cyclase inhibitors (MB and ODQ). In addition, the NO synthase substrate, L-arginine and the cGMP phosphodiesterase inhibitor, MY 5445 were seen to potentiate the effects of L-NAME. Thus, L-NAME used alone, has limitations as a specific inhibitor of the arginine-NOcGMP pathway and may therefore be a poor pharmacological tool for use in characterising participation in pathophysiological processes.

Key words: Carrageenin analgesia, NG-nitro-L-arginine methyl ester (L-NAME), Nitric oxide (NO), Guanosine 3',5'-monophophate cGMP, $1 \mathrm{H}-[1,2,4]$-oxadiazolo-[4,3-a] quinoxalin-1-one (ODQ), Inducible NO synthase (iNOS), Methylene blue (MB), NG-monomethyl-L-arginine (L-NMMA)

\section{L-NAME causes antinociception by stimulation of the arginine-NO-cGMP pathway}

\author{
I. D. G. Duarte ${ }^{1}$ and S. H. Ferreira ${ }^{2, C A}$
}

${ }^{1}$ Departamento de Farmacologia, Instituto de Ciências Biomédicas-UFMG, CEP 31270-901, Belo Horizonte, MG, Brazil; and ${ }^{2}$ Departamento de Farmacologia, Faculdade de Medicina de Ribeirão Preto-USP, CEP 14049-900, Ribeirão Preto, SP, Brazil

${ }^{\mathrm{CA}}$ Corresponding Author
Tel/fax: (+55) 166232792
Email: shferrei@fmrp.usp.br

\section{Introduction}

L-NAME ( $\mathrm{N}^{\mathrm{G}}$-nitro-L-arginine methyl ester), has been shown to cause antinociception by spinal, supraspinal, local (intraplantar) or systemic administration. ${ }^{1-8}$ As L-NAME is considered an specific nitric oxide (NO) synthase inhibitor, ${ }^{2,24}$ these experiments were taken to support the hypothesis that stimulation of the arginine/NO/cGMP pathway enhances nociception at various levels of the sensory system. On the other hand, there are several reports indicating that cholinergic or opioidergic stimulation of the arginine /NO/cGMP pathway causes central, spinal or peripheral analgesia, ${ }^{9-12}$ and some peripheral analgesics cause antinociception by stimulation of this pathway. ${ }^{13-16}$ Furthermore, the central analgesic, arginine, seems to be associated with NO-cGMP stimulation. ${ }^{17-19}$ Thus there appears to be an apparent contradiction amongst the various experiments made to ascertain the role of the arginine/NO/cGMP pathway in nociception. A great deal of information has been derived with the use of L-NAME as a methodological tool. How ever L-NAME can be seen to be either analgesic or hyperalgesic in the same test $\mathrm{t}^{20}$ 
whilst another NO synthase inhibitor $\mathrm{N}^{\mathrm{G}}$-monomethyl-L-arginine (L-NMMA) does not show antinociception in the same test as L-NAME, i.e. the formalin test in mice. ${ }^{2}$ Recently, L-NAME has been reported to stimulate inducible NO synthase (iNOS) gene expression. ${ }^{21}$ Because of these apparent contradictory results, we evaluated the possibility that the analgesic effect of L-NAME was due to stimulation of the arginine/NO/cGMP pathway. In the present study L-NAME was initially assayed in two tests in which nociception involves an inflammatory stimulus: the acetic acid induced writhings in mice and in the rat paw pressure hyperalgesia test induced by intraplantar administration of carrageenin. In these tests L-NAME showed an antinociceptive effect which was significantly inhibited by pretreatment of the animals with L-NMMA.

To further investigate the antinociceptive effect of L-NAME and in order to avoid the oedema formation and facilitate successive injections of drugs, $\mathrm{PGE}_{2}$ instead of carrageenin was used to induce hyperalgesia in the rat paw pressure test. In this test the peripheral antinociceptive synergism between L-NAME and the NO synthase substrate, arginine, and the cGMP phosphodiesterase inhibitor, as well the effect of two inhibitors of guanylate cGMP activation, methylene blue (MB) and 1H-[1,2,4]-oxadiazolo[4,3-a] quinoxalin-1-one (ODQ) was evaluated. Finally, since L-NAME has been shown to cause analgesia by intracerebroventricular administration, ${ }^{2}$ we tested L-NAME co-administration with inhibitors of the arginine/NO/cGMP pathway, L-NMMA, MB and ODQ.

\section{Materials and Methods}

\section{Animals}

The experiments were performed on male Wistar rats $(150-180 \mathrm{~g})$ and albino Swiss mice $(22-30 \mathrm{~g})$. The animals were housed under natural light, with free access to food and water. Intracerebroventricular (i.c.v.) injections in rats were made following the method described by Côrrea and Graeff. ${ }^{22}$ When single doses of the various drugs were used, they were based on dose response pilot experiments. All experimental procedures conformed to the IASP guidelines on the use of animals in pain research. Rats were used once only.

\section{Nociception tests}

\section{(a) Writhing test in mice.}

This test was based on the frequency of abdominal contortions evoked by an intraperitoneal injection of $10 \mathrm{ml} / \mathrm{kg}$ of $0.6 \%$ ace tic acid. ${ }^{8}$ L-NAME, L-arginine, or vehicle was injected $15 \mathrm{~min}$ before acetic acid administration, and the number of writhing events were counted for $20 \mathrm{~min}$ after the nociceptive challenge. For antagonism studies, mice were treated as above, except that L-NMMA was administered $15 \mathrm{~min}$ before L-NAME.

\section{(b) Hind paw hyperalgesia test in rats.}

Our modification of the Randall-Selitto rat paw pressure test was used to measure hyperalgesia. ${ }^{23}$ In the test, a pressure of $20 \mathrm{mmHg}$ is continuously applied to the hind paw of the rat until the animal presents a typical freezing reaction (reaction time). After measurement of the basal reaction time (control), hyperalgesia was induced either by an intraplantar injection of carrageenin $(\mathrm{Cg}, 100 \mu \mathrm{g})$ or $\mathrm{PGE}_{2}$. The intensity of hyperalgesia was quantified as the difference in reaction time (delta reaction time) measured $3 \mathrm{~h}$ after administration of $\mathrm{Cg}$, from the control reaction time assessed before injection of the hyperalgesic stimulus. The term nociception is used in this paper to describe the presence of an overt standard behaviour induced by the application of a noxious stimulus in a normal tissue or a non-nox ious stimulus in previously sensitised tissue. The term hyperalgesia is used when a non-nox ious stimulus causes nociception when applied to a sensitized tissue either by an inflammatory stimulus like carrageenin or an hyperalgesic mediator like prostaglandin E2.

\section{Drugs}

Carrageenin (Viscarin) was purchased from Marine Colloids, EUA. L-NAME (N-nitro-L-arginine methyl ester, Wellcome, UK) and L-NMMA (N ${ }^{\mathrm{G}}$-monomethylL-arginine acetate) were purchased from Sigma ( $\mathrm{St}$ Louis, MO, USA) and methylene blue (MB) was from Reagen (Brazil) and ODQ (1H-[1,2,4]-oxadiazolo[4,3-a] quinoxalin-1-one) was from Tocris Cookson Inc. (St Louis, USA).

\section{Statistics}

All results are presented as means (SEM of five rats or six to 12 mice per group. Results are presented as means and standard errors of the means of groups of at least five animals in each group. Differences between responses were evaluated by ANOVA, followed by the Bonferroni $t$-test. Results with $P<0.05$ were considered significant.

\section{Results}

Blockade of L-NAME effect by L-NMMA in two tests of nociception induced by inflammatory stimuli

(a) Mice writhing test: nociceptive behaviour induced by intraperitoneal acetic acid administration.L-NAME administered intraperitoneally reduced the number of abdominal constrictions in a dose-dependent manner 


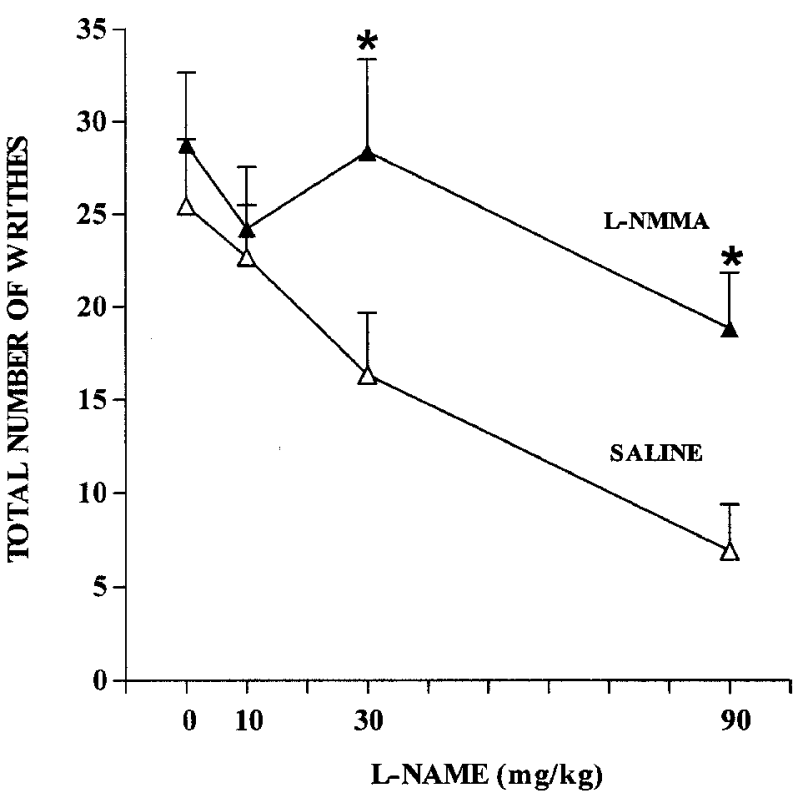

FIG. 1. Inhibition by L-NMMA $(10 \mathrm{mg} / \mathrm{kg}$, i.p.) of the antinociceptive effect of intraperitoneal administration of L-NAME on the acetic acid writhing test in mice. The symbols are the mean \pm SEM of $6-12$ mice/group. *indicates significant differences $(P<0.05)$ in comparison with the control L-NAME group treated with intraperitoneal saline.
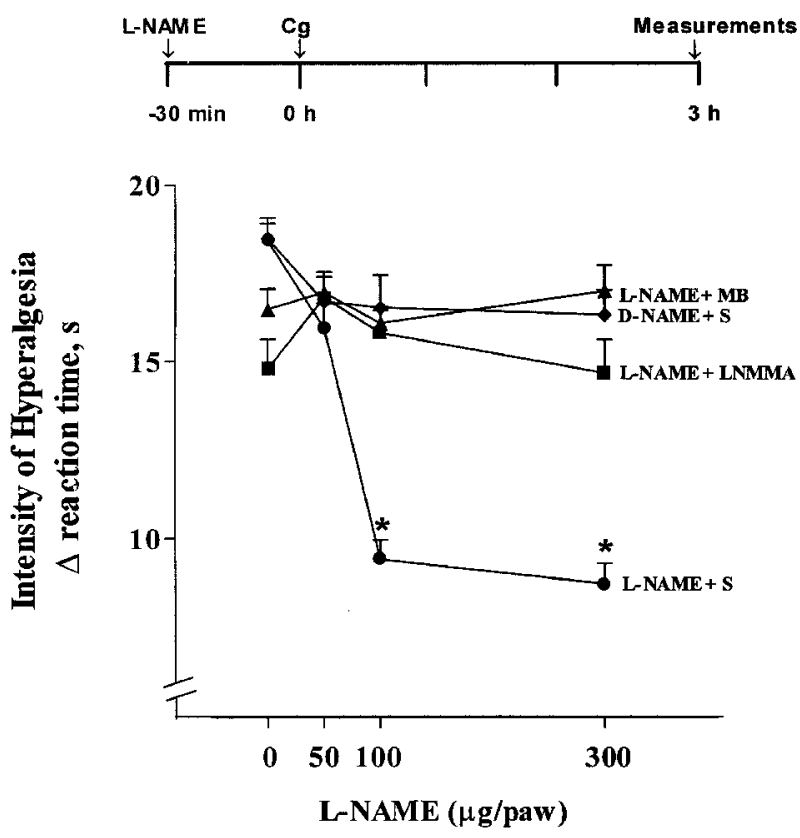

FIG. 2. Antinociceptive effect of intraplantar administration of L-NAME but not of D-NAME on carrageenin-induced hyperalgesia and the blockade of antinociception by local L-NMMA and methylene blue (MB) co-administration. L-NMMA $(100 \mu \mathrm{g} / \mathrm{paw}), \mathrm{MB}(500 \mu \mathrm{g} / \mathrm{paw})$ or saline (S) were injected $30 \mathrm{~min}$ before carrageenin $(\mathrm{Cg}, 100 \mu \mathrm{g} / \mathrm{paw})$. L-NAME or D-NAME $(50-300 \mu \mathrm{g} / \mathrm{paw})$ were also injected $30 \mathrm{~min}$ before $\mathrm{Cg}$, and the intensity of hyperalgesia was measured $3 \mathrm{~h}$ after the hyperalgesic stimulus (see injections diagram). The symbols are the mean + SEM of five rats/ group. *indicates significant differences $(P<0.01)$ in comparison with the control (saline, O) or treatment with L-NAME, MB, D-NAME. by approximately $40 \%$ and $73 \%$ at doses of 30 and $90 \mathrm{mg} / \mathrm{kg}$, respectively. L-NMMA (10 mg/kg i.p.), significantly blocked the antinociceptive action of L-NAME, but had no effect on its own (Fig. 1).

\section{(b) Rat paw pressure test: hyperalgesia induced by carrageenin inflammation.}

Intraplantar administration of L-NAME ( 50 and $300 \mu \mathrm{g}$ ) produced a significant inhibition of carrageenininduced hyperalgesia of up to $40 \%$ for the highest dose used (Fig. 2). L-NAME-induced peripheral hyperalgesia was significantly inhibited by pre-treatment of the paws with $100 \mu \mathrm{g}$ of L-NMMA or $500 \mu \mathrm{g}$ of MB. Neither MB, nor L-NMMA (up to $500 \mu \mathrm{g} / \mathrm{paw}$ ) had hyperalgesic effects.

Rat paw pressure test: hyperalgesia induced by $\mathrm{PGE}_{2}$

(a) Antagonism L-NMMA, MB or ODQ of

L-NAME-induced antinociception.

Pilot experiments showed that doses higher than $200 \mu \mathrm{g} / \mathrm{paw}$ were needed to give significant antinociception. Fig. 3 shows a significant antinociceptive
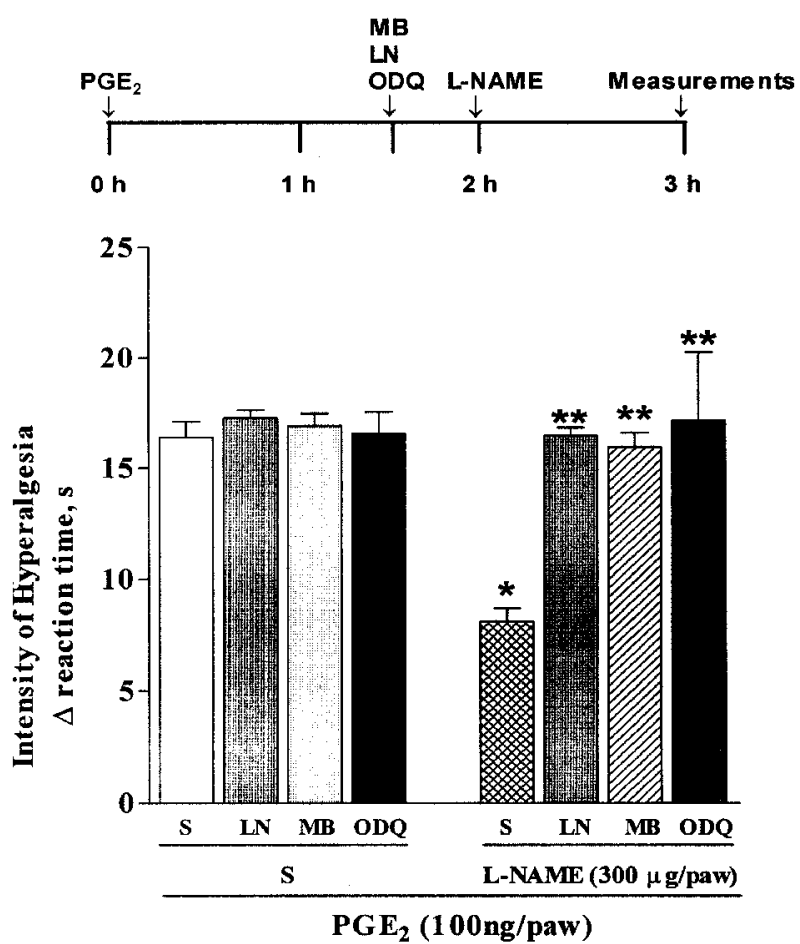

FIG. 3. Blockade by L-NMMA (LN) and guanylate cyclase inhibitors (MB and $O D Q$ ) of the antinociceptive effect of L-NAME on $\mathrm{PGE}_{2}$ induced hyperalgesia. $\mathrm{PGE}_{2}$ was injected at time zero, saline (S) or LN, MB,ODQ, at time $1.5 \mathrm{~h}$ and L-NAME or $\mathrm{S} 2 \mathrm{~h}$ after $\mathrm{PGE}_{2}$. The insert shows the antinociceptive effect of L-NAME $(60=a, 180=b$ and $300 \mu \mathrm{g}$ per paw $=c$ ). The bars and symbols are the mean \pm SEM of five rats/group. The asterisks mean significant differences $(P<$ $0.05)$ : (a) *in comparison with the control $\mathrm{PGE}_{2}$; (b) **in comparison with L-NAME-treated groups. 


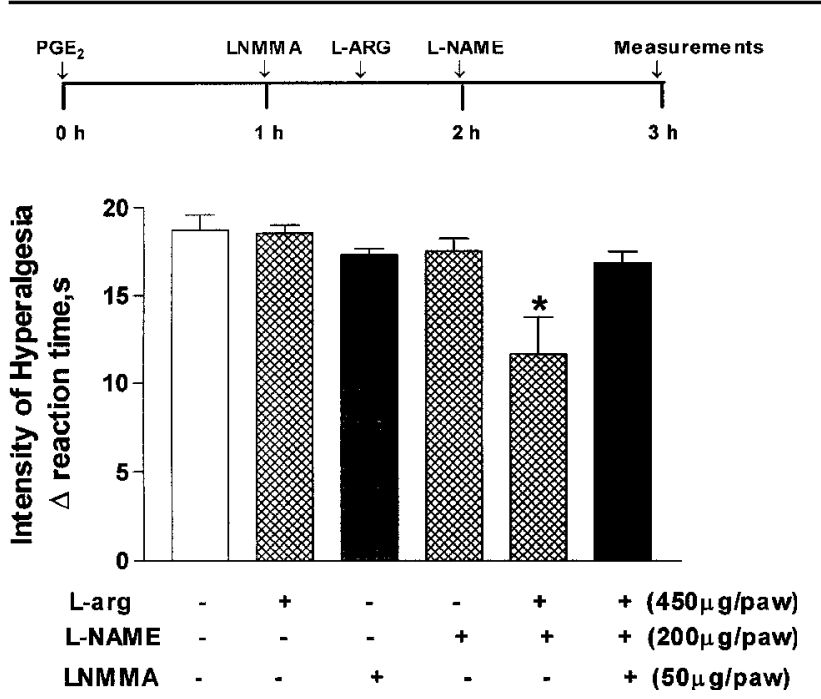

FIG. 4. Antinociceptive synergism between L-NAME and $\mathrm{L}$-arginine. The measurements were made $3 \mathrm{~h}$ after the intraplantar injections of $\mathrm{PGE}_{2}(100 \mathrm{ng} / \mathrm{paw})$. L-NMMA, L-Arginine (L-Arg) and L-NAME were injected into the paw 1 , 1.5 and $2 \mathrm{~h}$ after the $\mathrm{PGE}_{2}$ challenge, respectively. The bars are the mean \pm SEM of five rats/group. The asterisks mean significant differences $(P<0.05)$ : (a) *in comparison with the control PGE ${ }_{2}$ treated either with L-arg, L-NAME, or saline (S); (b) **in comparison with the group which received L-NMMA + L-arg + L-NAME.

effect upon hyperalgesia induced by $\mathrm{PGE}_{2}$ of a dose of $300 \mu \mathrm{g}$ of L-NAME. Pretreatment of the paws with L-NMMA (LN), MB or ODQ prevented the antinocic ep tive effect of L-NAME.

\section{(b) Arginine and MY 5445 enhancement of L-NAME effects.}

Figure 4 shows that the association of L-arginine and L-NAME treatments caused a significant antinociception compared with single treatments. There was no difference among controls groups. L-NMMA significantly inhibited the antinociceptive effect of the association of L-arginine and L-NAME treatment. The association of the same doses of L-NAME and D-arginine did not cause antinociception as compared with the single treatment (data not shown).

Figure 5 shows that MY 5445 enhanced, in a doserelated manner, the antinociceptive effect of L-NAME. A dose of $180 \mu \mathrm{g}$, which did not produce antinociception in our experiments, produced an effect similar to $300 \mu \mathrm{g}$ when the paws were pretreated with MY 5445 (compare with Fig. 3).

\section{(c) Blockade of the intracerebroventricular antinociceptive effect of L-NAME by co-treatment with $L-N M M A, M B$ or $O D Q$.}

L-NAME, when administered i.c.v. at a dose of $300 \mu \mathrm{g}$ per rat, produced potent antinociception in paws rendered hyperalgesic by $\mathrm{PGE}_{2}$ (Fig. 6). This L-NAMEinduced anti-hyperalgesic effect was abolished by coi.c.v. administration of L-NMMA $(300 \mu \mathrm{g}), \quad \mathrm{MB}$ $(400 \mu \mathrm{g})$ and ODQ $(8 \mu \mathrm{g})$. Neither L-NMMA, nor MB,
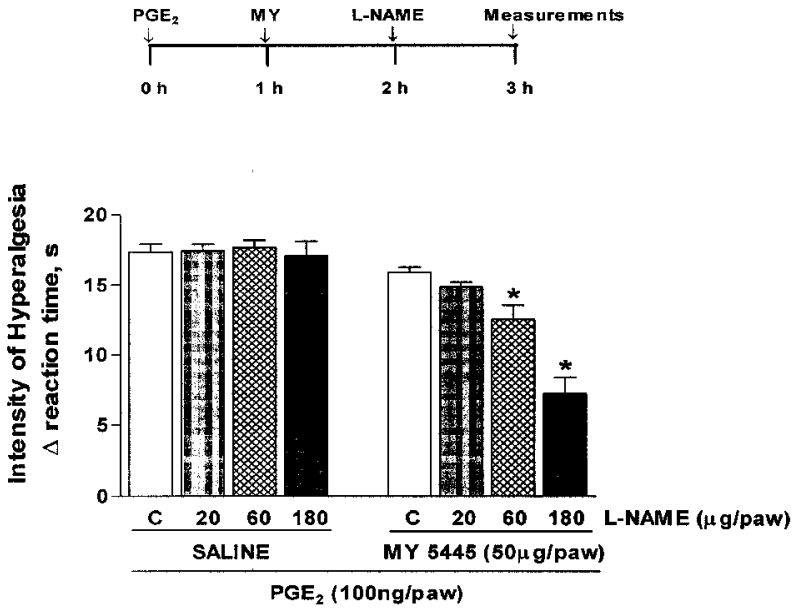

FIG. 5. Potentiation of intraplantar injections of L-NAME by the cGMP phosphodiesterase inhibitor, MY 5445. The measurements were made $3 \mathrm{~h}$ after the intraplantar injections of $\mathrm{PGE}_{2}$ (100 ng/paw). MY 5445 and (or) L-NAME were injected into the paw 1 and $2 \mathrm{~h}$ after $\mathrm{PGE}_{2}$, respectively. The bars are the mean \pm SEM of five rats/group. The asterisk means significant differences $(P<0.05)$ compared with respective doses of L-NAME. There was no significant differences between the controls groups (C) treated with saline or MY 5445 .
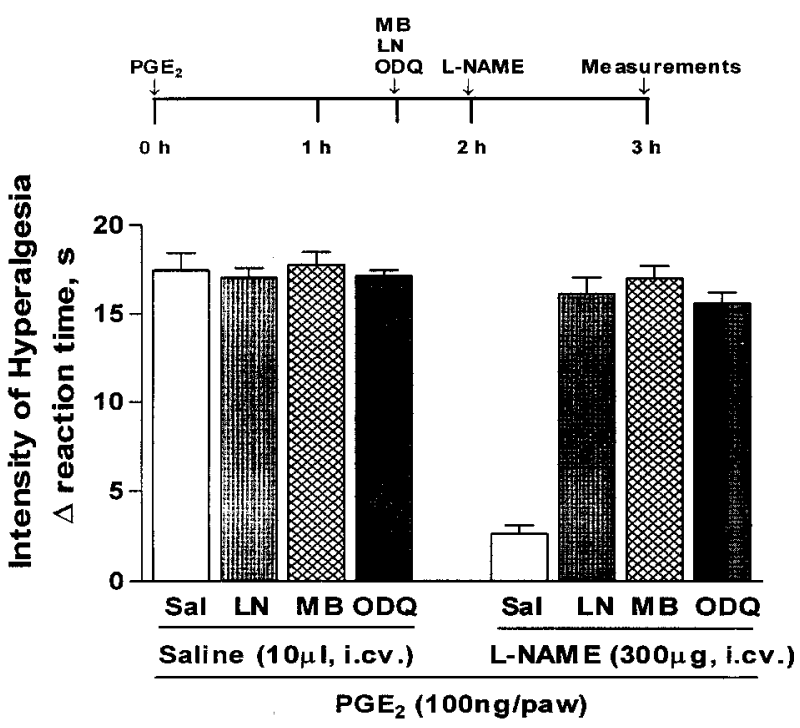

FIG. 6. Antinociceptive effect of intracerebroventricular administration of L-NAME ( $N^{G}$-nitro-L-arginine methyl ester) on $\mathrm{PGE}_{2}$-induced hyperalgesia, and its blockade by i.c.v. L-NMMA (LN, $300 \mu \mathrm{g})$ ), MB $(400 \mu \mathrm{g})$ or ODO $(8 \mu \mathrm{g})$. These drugs and vehicle were co-injected with L-NAME $2 \mathrm{~h}$ after $\mathrm{PGE}_{2}$ (100 ng/paw). The intensity of hyperalgesia was measured $1 \mathrm{~h}$ after the i.c.v. injections. The bars are the mean, SEM of five rats/group. ${ }^{*},{ }^{*}$ mean significant differences $(P<$ 0.01 ) in comparison with the saline- (Sal) or L-NAME-treated group, respectively.

nor ODQ had any effects on $\mathrm{PGE}_{2}$ induced hyperalgesia.

\section{Discussion}

L-NAME has been show $n$ by several laboratories ${ }^{1-8}$ to have a peripheral and central antinociceptive action. 
Here, we confirm their observations using two tests of nociception. In the acetic acid writhing test, systemic administration (i.p.) of L-NAME but not L-NMMA caused an antinociceptive effect (Fig. 1). In addition, we showed that L-NMMA inhibited the antinociceptive activity of L-NAME in this test as well as in the rat paw pressure test in which hyperalgesia was induced either by an inflammatory stimuli like $\mathrm{Cg}$ or by an hyperalgesic mediator, $\mathrm{PGE}_{2}$ (Figs 2-4). The D-is o mer of NAME showed no antinocicep tive activity (Fig. 2) in carrageenin-induced hyperalgesia in the rat pressure tests (Fig. 2). It has already been shown that this isomer had no antinociceptive effect in other tests. ${ }^{2}$ Co-injection of L-NMMA i.c.v. also inhibited the central analgesic action of L-NAME (Fig. 6).

The observed antinociceptive effect of L-NAME apparently supports the idea that the arginine/NO/ cGMP pathway contributes to nociception induced by inflammatory stimuli, particularly because L-NAME is considered to be a selective NO synthase inhibitor. $^{2,24}$ L-arginine-derived inhibitors, however, have been found to have bizarre pharmacological effects. For instance, it has been de monstrated that L-NAME is a poor inhibitor of L-arginine transport, whereas L-NMMA and L-NIO substantially inhibit this event. ${ }^{25}$ Moreover, L-NAME, but not L-NMMA, is a muscarinic antagonist. ${ }^{26}$ On the other hand, L-NMMA, has been shown to behave as a partial agonist, since it antagonizes NO synthesis in some tissues, but stimulates $\mathrm{NO}$ synthesis in isolated arterial rings. ${ }^{27}$

Since, in our experiments, L-NMMA in the doses used did not show any effect per se, but blocked the antinociceptive effect of L-NAME, we assume that it may be acting as a NO synthase inhibitor. On the other hand, L-NAME may be acting either as a substrate for or as an iNOS stimulator.

It is know $n$ that during carrageenin (but not $\mathrm{PGE}_{2}$ ) induced hyperalgesia the arginine/NO/cGMP pathway is activated. ${ }^{28}$ The absence of activity of the arginine $\mathrm{NO}$ cGMP pathway in $\mathrm{PGE}_{2}$-induced hyperalgesia is illustrated here by the fact that neither the NO synthase inhibitors (MB or ODQ) nor the cGMP phosphodiesterase inhibitor, MY5445, have any effect upon control hyperalgesia (Figs 3-5). Nevertheless, L-NAME displayed an antinociceptive effect. Recently, L-NAME has been described as acting as a partial agonist, ${ }^{27}$ causing rapid induction of iNOS gene expression. ${ }^{21}$ Stimulation of NO synthesis may explain the observed L-NAME antinociception, in models like those used in this investigation. In these models it has been previously shown that either NO donors or drugs which stimulate the arginine NO cGMP pathway cause analgesia. ${ }^{9,10,13-18}$ Thus, the simplest comprehensive explanation for the fact that L-NAME antinociception was inhibited by a NO synthase inhibitor, L-NMMA and was abolished by guanylate cyclase inhibitors, MB or ODQ as well as potentiated by either the NO synthase substrate, arginine or by the cGMP phosphodiesterase inhibitor MY5445 is that L-NAME is activating iNOS. The fact that i.c.v. co-injections of $\mathrm{MB}$ or ODQ inhibited the central antinociceptive effect of L-NAME suggests a similar mechanism of action for the peripheral and central action for this agent.

Finally, it must be pointed out that, in contrast with the results presented here, there are several observations indicating that the intraplantar or systemic administration of L-NAME has similar effects to other NO synthase inhibitors in causing antinociception. ${ }^{4,20}$ This contradiction may explained by considering that the activation of the arginine/NO/cGMP pathway causes hyperalgesia or analgesia depending on the predominant type of fibres involved in the nociceptive response or depending on the tissue level of NO. ${ }^{20}$ From the therape utic point of view, however, it seems that during inflammatory pain in man, the activation of the arginine/NO/cGMP pathway causes analgesia. This suggestion is in line with the observations that $\mathrm{NO}$ donors are either effective as analgesics by themselves or in conjunction with other analgesics. ${ }^{29-32}$

In conclusion, the present study confirms that L-NAME causes analgesia and demonstrated that L-NMMA, another NO synthase inhibitor, significantly blocked both the peripheral and central antinociceptive actions of L-NAME in rats and mice. L-NAME antinociception was also blocked by inhibitors of guanilate-cyclase activation and potentiated by arginine and by a cGMP phosphodiesterase inhibitor. These results allow us to speculate that L-NAME causes antinociception by acting as a partial agonist, thus stimulating iNOS activation in the nociceptive tests used. Furthermore our results draw into question the use of L-NAME alone as a methodological tool to characterise the nociceptive role of the arginineNO-cGMP pathway in physiopathological processes, in the absence of confirmation with another NO synthase inhibitor.

\section{Acknowledgements}

The authors thank I.R. dos Santos for technical assistance. This work was supported by FAPESP (Fundaçäo de Amparo à Pesquisa do Estado de São Paulo), FINEP (Financiadora de Estudos e Projetos), FIPEC (Fundo de Incentivo à Pesquisa TécnicoCientífica do Banco do Brasil) and CNPq (Conselho Nacional de Desenvolvimento Científico e Tecnológico).

\section{References}

1. Moore PK, Oluyomi AO, Babbedge RC, Wallace P, Hart SL. L-N ${ }^{G}$-nitro arginine methyl ester exhibits antinociceptive activity in the mouse. $\mathrm{Br}$ J Pharmacol 1991; 102: 198-202.

2. Babbedge RC, Hart SL, Moore PK. Anti-nociceptive activity of nitric oxide synthase inhibitors in the mouse: dissociation between the effect of L-NAME and L-NMMA. J Pharm Pharmacol 1993; 45: 77-79. 
3. Roche AK, Cook M, Wilcox GL, Kajander KC. A nitric oxide synthesis inhibitor (L-NAME) reduces licking behaviour and Fostabeling in the spinal cord of rats during formalin-induced inflammation. Pa in 1996; 66: 331-341.

4. Malmberg AB, Yaksh TL Spinal nitric oxide synthesis inhibition blocks NMDA-induced thermal hyperalgesia and produces antinociception in the formalin test in rats. Pain 1993; 54: 291-300.

5. Sakurada T, Sugiyama A, Sakurada C, et al. Effect of spinal nitric oxide inhibition on capsaicin-induced nociceptive response. Life Sci 1996; 59: 921-930.

6. Yonehara N, Takemura M, Yoshimura M, et al. Nitric oxide in the rat spinal cord in Fre und's adjuvant-induced hyperalgesia. Jpn J Pharm acol 1997; 75: 327-335.

7. Gao WC, Qiao JT. Nitric oxide contributes to both spinal nociceptive transmission and its descending inhibition in rats: an immunocytochemical study. Neurosci Lett 1998; 240: 143-146.

8. Shibuta S, Mashimo T, Zhang P, Ohara A, Yoshiya I. A new nitric oxide donor, NOC-18, exhibits a nociceptive effect in the rat formalin model. I Neurol Sci 1996; 141: 1-5.

9. Duarte ID, Lorenzetti BB, Ferreira SH. Peripheral analgesia and activation of the nitric oxide-cyclic GMP pathway. Eur J Pharmacol 1990; 186 $289-293$.

10. Duarte ID, Ferreira SH. The molecular mechanism of central analgesia induced by morphine or carbachol and the L-arginine-nitric oxide-cGMP pathway. Eur J Pharmacol 1992; 221: 171-174.

11. Iwamoto ET, Marion L. Pharmacological evidence that nitric oxide mediates the antinociception produced by muscarinic agonists in the rostral ventral medulla of rats. J Pharmacol Exp Ther 1994; 269: 699-708.

12. Xu Z, Tong C, Pan HL, Cerda SE, Eisenach JC. Intravenous morphine increases release of nitric oxide from spinal cord by an alpha-adrenergic and cholinergic mechanism. J Neurophysiol 1997; 78: 2072-2078.

13. Ferreira SH, Duarte ID, Lorenzetti BB. The molecular mechanism of action of peripheral morphine analgesia: stimulation of the cGMP system via nitric oxide release. Eur J Pharmacol 1991; 201: 121-122.

14. Tonussi CR, Ferreira SH. Mechanism of diclofenac analgesia: direct blockade of inflammatory sensitization. Eur J Pharmacol 1994; 251: $173-179$.

15. Granados-Soto V, Rufino MO, Gomes Lopes LD, Ferreira SH. Evidence for the involvement of the nitric oxide-cGMP pathway in the antinociception of morphine in the formalin test. Eur J Pharmacol 1997; 340: $177-180$.

16. Lorenzetti BB, Ferreira SH. Activation of the arginine-nitric oxide pathway in primary sensory neurons contributes to dipyrone-induced spinal and peripheral analgesia. Inflam $m$ Res 1996; 45: 308-311.

17. Ji XQ, Zhu XZ. Possible involvement of nitric oxide in arginine-induced analgesia. Chung Kuo Yao Li Hsueh Pao 1993; 14: 289-291.
18. Kumar A, Raghubir R, Srimal RC, Dhawan BN. Evidence for involvement of nitric oxide in pretectal analgesia in rat. Neuroreport 1993; 4: 706-708.

19. Hentall ID. Excitation of cells in the rostral medial medulla of the rat by the nitric oxide-cyclic guanosine monophosphate messenger system. Neurosci Lett 1995; 195: 155-158.

20. Kawabata A, Manabe S, Manabe Y, Takagi H. Effect of topical administration of L-arginine on formalin-induced nociception in the mouse: a dual role of peripherally formed $\mathrm{NO}$ in pain modulation. $\mathrm{Br} J$ Pharmaco 1994; 112: 547-550

21. Miller MJ, Thompson JH, Liu X, et al. Failure of L-NAME to cause inhibition of nitric oxide synthesis: role of inducible nitric oxide synthase. Inflamm Res 1996; 45: 272-276.

22. Côrrea FM, Graeff FG. Central mechanism of the hypertensive action of intraventricular bradykinin in the unanaesthetized rat. Neuropharmacol 1974; 13: 65.

23. Ferreira SH, Lorenzetti BB, Correa FM. Central and peripheral antialgesic action of aspirintike drugs. Eur J Pharmacol 1978; 53: 39-48.

24. Rees DD, Palmer RM, Schulz R, Hodson HF, Moncada S. Characterization of three inhibitors of endothelial nitric oxide synthase in vitro and in vivo. Br J Pharmacol 1990; 101: 746-752.

25. Bogle RG, Moncada S, Pearson JD, Mann GE. Identification of inhibitors of nitric oxide synthase that do not interact with the endothelial cell L-arginine transporter. Br J Pharmacol 1992; 105: 768-770.

26. Buxton IL, Cheek DJ, Eckman D, Westfall DP, Sanders KM, Ke ef KD. NGnitro L-arginine methyl ester and other alkyl esters of arginine are muscarinic receptor antagonists. Circ Res 1993; 72: 387-395.

27. Archer SL, Hampl V. NG-monomethyl-L-arginine causes nitric oxide synthesis in isolated arterial rings: trouble in paradise. Biochem Biophys Res Commun 1992; 188: 590-596.

28. Cunha FQ, Teix eira MM, Ferreira SH. Pharmacological modulation of secondary mediator systems-cyclic AMP and cyclic GMP-on inflammatory hyperalgesia. Br J Pharmacol 1999; 127: 671-678.

29. Lauretti GR, Lima IC, Reis MP, Prado WA, Pereira NL. Oral ketamine and transdermal nitroglycerin as analgesic adjuvants to oral morphine therapy for cancer pain management. Anesthesiology 1999; 90: $1528-1533$.

30. Lauretti GR, de Oliveira R, Reis MP, Mattos AL, Pereira NL Transdermal nitroglyce rine enhances spinal sufentanil postoperative analgesia following orthopedic surgery. Anesthesiology 1999; 90: 734-739.

31. Berrazueta JR, Losada A, Poveda J, et al. Successful treatment of shoulder pain syndrome due to supraspinatus tendinitis with transdermal nitroglycerin. A double blind study. Pain 1996; 66: 63-67.

32. Berrazueta JR, Poveda JJ, Ochoteco J, et al. The anti-inflammatory and analgesic action of transdermal glyceryltrinitrate in the treatment of infusion-related thrombophlebitis. Postgrad Med J 1993; 69: $37-40$. 


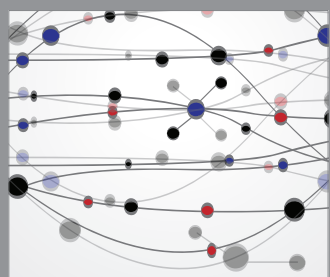

The Scientific World Journal
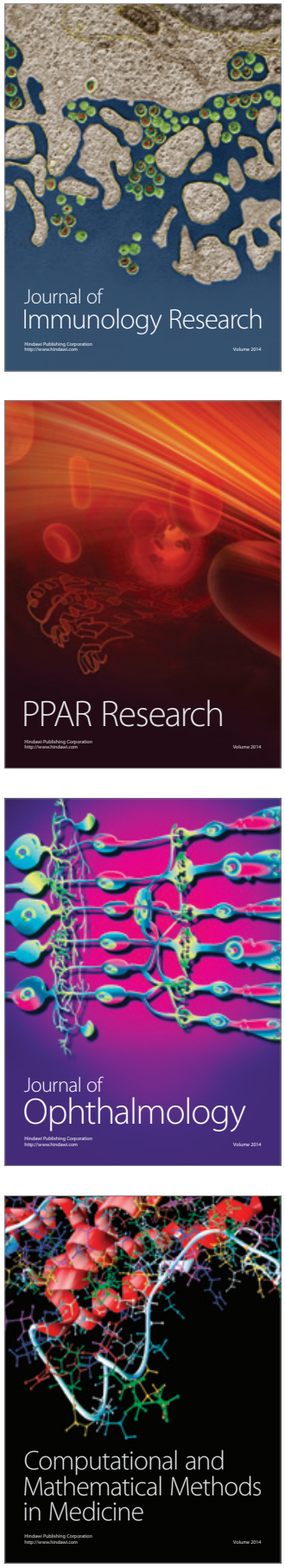

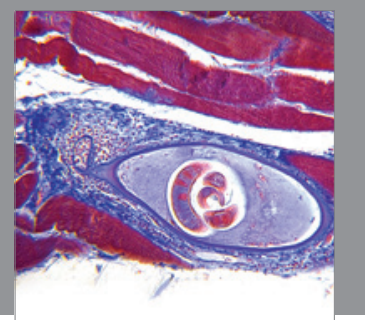

Gastroenterology

Research and Practice
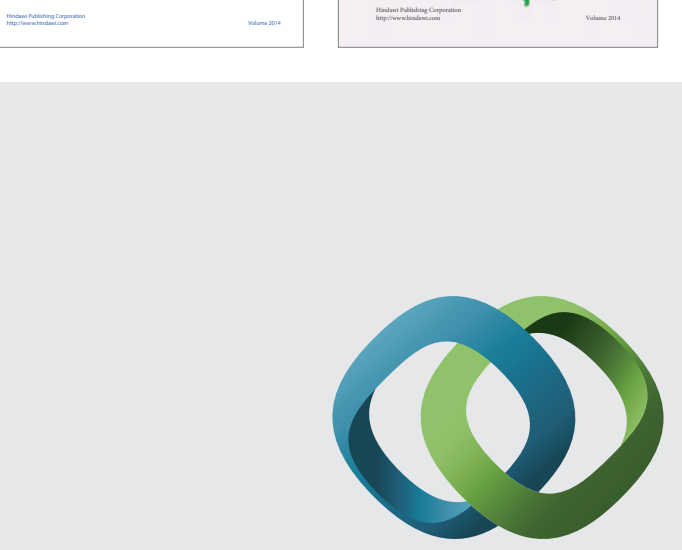

\section{Hindawi}

Submit your manuscripts at

http://www.hindawi.com
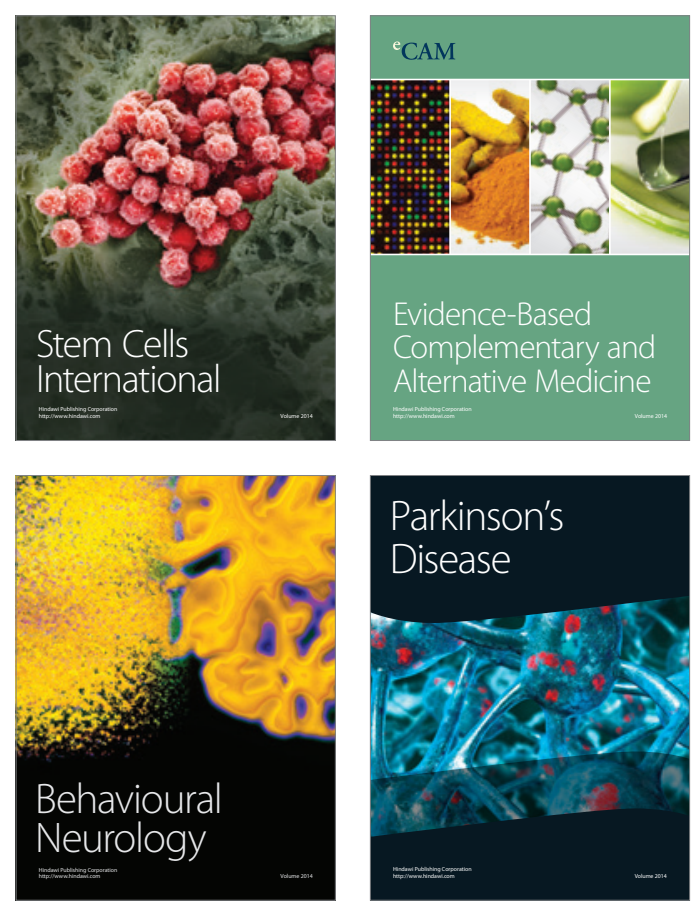

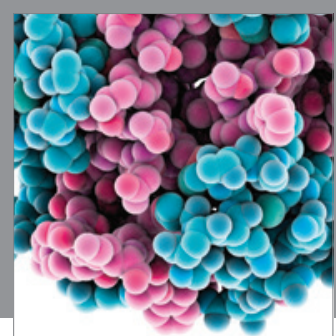

Journal of
Diabetes Research

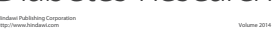

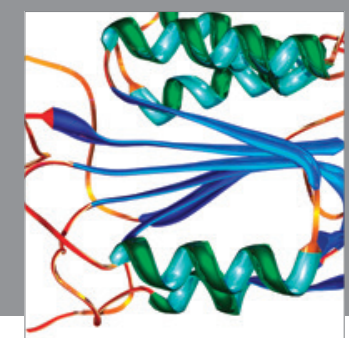

Disease Markers
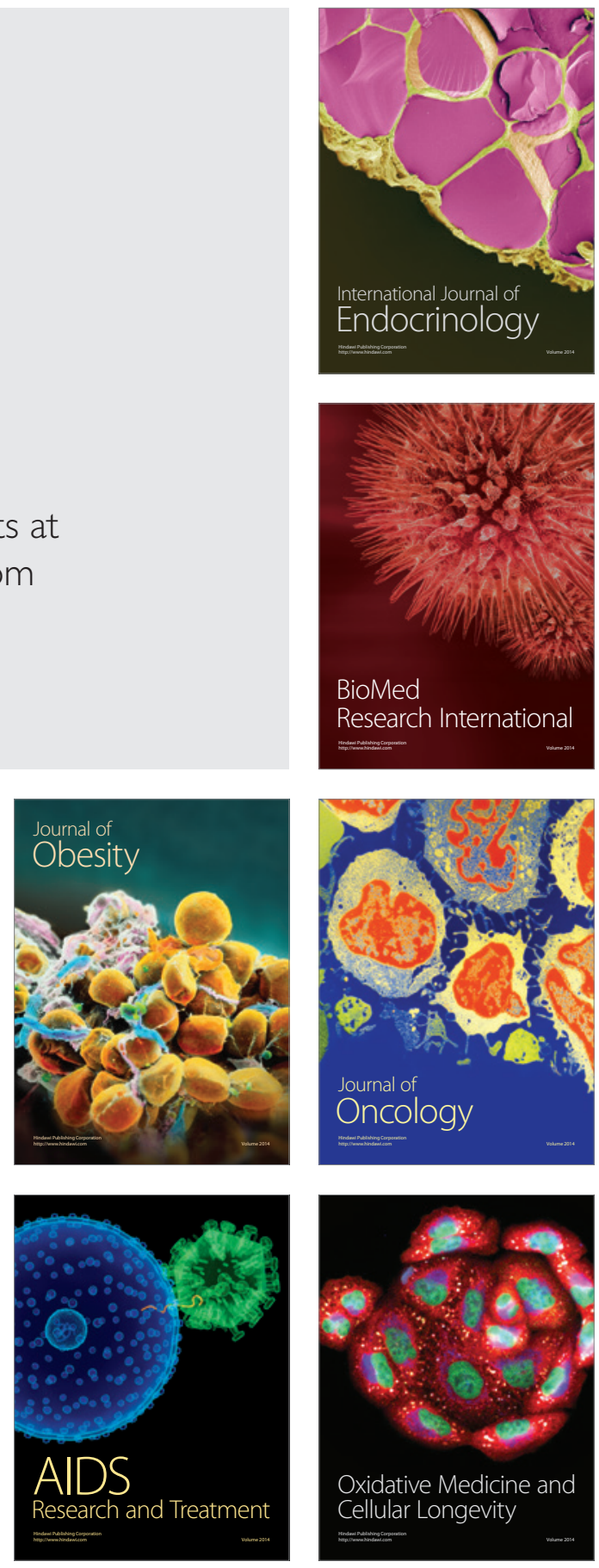